CLINICAL STUDY

\title{
Vitamin D in relation to metabolic risk factors, insulin sensitivity and adiponectin in a young Middle-Eastern population
}

\author{
Marie-Hélène Gannagé-Yared ${ }^{1}$, Rima Chedid ${ }^{2}$, Simon Khalife ${ }^{3}$, Emmanuel Azzi ${ }^{1}$, Fernand Zoghbi ${ }^{2}$ \\ and Georges Halaby ${ }^{1}$ \\ Departments of ${ }^{1}$ Endocrinology, ${ }^{2}$ Biochemistry and ${ }^{3}$ Biostatistics, Saint-Joseph University, Beirut, Lebanon \\ (Correspondence should be addressed to M-H Gannagé-Yared who is now at Division of Endocrinology, Hôtel-Dieu de France Hospital, Adib Ishaac \\ Street, Beirut, Lebanon; Email: mhcyared@terra.net.lb)
}

\begin{abstract}
Objectives: Several studies suggest a link between circulating 25-hydroxyvitamin D (25(OH)D) and metabolic risk factors. However, this relation has been mainly studied in elderly and/or obese subjects. In addition, the relation between $25(\mathrm{OH}) \mathrm{D}$ and adiponectin is unclear. The purpose of this study is to look at these relations in non-obese young individuals.

Design: We investigated the relation between serum 25(OH)D and adiposity, blood pressure, glucose metabolism, lipid profile, and adiponectin in 381 randomly selected university students (201 males and 180 females, mean age $23.9 \pm 3.9)$.

Results: In the overall population, $25(\mathrm{OH}) \mathrm{D}$ is significantly inversely correlated with body mass index (BMI), systolic blood pressure (SBP), waist circumference (WC), fasting plasma glucose (FPG), insulin levels, and homeostasis model assessment of insulin resistance (HOMA index) and positively correlated with adiponectin and high density lipoprotein-cholesterol $(P<0.01$ for all variables). In males, these correlations are still significant for BMI, SBP, WC, and adiponectin $(P=0.02, P=0.01, P=0.04$ and $P=0.01$ respectively); also, $25(\mathrm{OH}) \mathrm{D}$ is inversely correlated with low density lipoprotein (LDL)cholesterol $(P=0.007)$. In females, $25(\mathrm{OH}) \mathrm{D}$ is only inversely correlated with FPG and HOMA index $(P<0.001$ and $P=0.03$ respectively). In multivariate regression analysis models, after adjustment for sex and BMI, 25(OH)D is an independent predictor of FPG and SBP $(P=0.032$ and $P=0.05$ respectively) in the overall population, while in males $25(\mathrm{OH}) \mathrm{D}$ is a predictor of LDL-cholesterol and SBP independently of BMI ( $P=0.007$ and $P=0.035$ respectively).

Conclusion: In non-obese young subjects, we observe new relationships between 25(OH)D and several metabolic risk factors and adiponectin. Further research is needed to elucidate the gender differences and to look at the relation between $25(\mathrm{OH}) \mathrm{D}$ and adiponectin.
\end{abstract}

European Journal of Endocrinology $160965-971$

\section{Introduction}

In addition to its essential role in bone health, vitamin D has multiple extraskeletal beneficial effects (1). Among these effects, several studies in adults suggest a link between vitamin $\mathrm{D}$ and cardiovascular disease risk (2-4), diabetes or HbA1c levels $(5,6)$, hypertension (7-10), and dyslipidemia (4). Reduced circulating 25-hydroxyvitamin D (25(OH)D) concentrations were found to be associated with higher fasting serum glucose $(11,12)$, reduced insulin sensitivity (13-15), increased risk of type 2 diabetes $(5,16,17)$ and either increased risk $(18,19)$ or no effect on the metabolic syndrome (MetS) $(20,21)$. On the other hand, results from interventional studies are controversial, showing either no effect of vitamin D supplementation on the risk of developing diabetes (22) or an attenuation of the increase in glycemia and insulin resistance that occur over time (23).

Definite conclusions from all the observational studies are limited because of the considerable variability in studied cohorts and, often, because of the lack of adjustment for important confounders, such as adiposity. In addition, most of the studies were performed in adult patients with glucose intolerance, diabetes or obesity. To our knowledge, very few studies have been performed in young non-obese individuals (13).

Moreover, the relation between circulating 25(OH)D and adiponectin has only been reported in a recent study performed in non-diabetic adults and where a positive relationship was found between the two variables (24). 
The purpose of this study is to look at the relation between 25(OH)D levels and body mass index (BMI), insulin sensitivity, blood pressure, lipid parameters, and adiponectin in a population of young healthy non-obese individuals.

\section{Materials and methods}

\section{Participants}

Participants are students recruited from the SaintJoseph University Medical Sciences Campus, located in Beirut. Three hundred and eighty one randomly selected students (201 males and 180 females) out of the 390 initially selected ones of both genders accepted to participate in the study. Population age ranged between 18 and 30 years, with a mean of $23.9 \pm 3.9$ years.

Every participant signed a written and informed consent that had been previously approved by our University Ethical Committee. Exclusion criteria were pregnancy, use of contraceptive pills or of drugs that may affect lipid profile and/or metabolic parameters.

The following anthropometric measures, performed using the same devices throughout this study, were taken by a registered nurse: height in meters, weight in kilograms (kg) using a manual scale, and waist circumference (WC), taken at the umbilicus, in centimeters $(\mathrm{cm})$. Systolic blood pressure $(\mathrm{SBP})$ and diastolic blood pressure (DBP) were measured in seated subjects after a rest for at least 15 min using a mercury tensiometer. BMI was calculated as weight in $\mathrm{kg} / \mathrm{squared}$ height in meters. Subjects were classified as MetS positive according to the Adult Treatment Panel III criteria (25) whenever at least three out of the five following risk factors were found: increased WC $>$ $102 \mathrm{~cm}$ in men and $>88 \mathrm{~cm}$ in women, elevated serum triglycerides $\geq 1.70 \mathrm{mmol} / \mathrm{l}$, reduced serum high density lipoprotein (HDL)-cholesterol $<1.04 \mathrm{mmol} / \mathrm{l}$ in men and $1.30 \mathrm{mmol} / \mathrm{l}$ in women, fasting plasma glucose $(\mathrm{FPG}) \geq 6.1 \mathrm{mmol} / \mathrm{l}$, elevated $\mathrm{SBP} \geq 130 \mathrm{mmHg}$ and/or DBP $\geq 85 \mathrm{mmHg}$.

Exercise level was evaluated according to the following score: 0 for no exercise, 1 for $30 \mathrm{~min}$ of exercise less than twice weekly, 2 for 30 min of exercise between two and five times weekly and 3 for $30 \mathrm{~min}$ of exercise more than five times weekly.

\section{Biological parameters}

Peripheral blood was collected after a $12 \mathrm{~h}$ fasting period. Collection was done mainly during the winter (158 subjects), spring (126 subjects), and fall (76 subjects) seasons. Only 21 blood samples were collected during summer; this is mainly due to the summer vacations of the students. In the hour following blood withdrawal, samples were centrifuged and serum was divided in several aliquots: some were stored at $-80{ }^{\circ} \mathrm{C}$ for insulin, adiponectin and $25(\mathrm{OH}) \mathrm{D}$ measurements later, and others were sent for biochemical analysis. Biochemical parameters (glucose, total-cholesterol, triglycerides, and HDL-cholesterol) were measured using an automated COBAS Integra 400, Roche Diagnostics. Low density lipoprotein (LDL)-cholesterol was then calculated using the Friedwald equation. 25(OH)D was measured using the Dia Sorin RIA (Stillwater, MN, USA). The assay sensitivity was $1.5 \mathrm{ng} / \mathrm{ml}$ and intraassay coefficient of variation $(\mathrm{CV})$ was below $12 \%$. Fasting insulin level was measured using a commercial chemiluminescent assay (Immulite, DPC, Los Angeles, CA, USA). The assay sensitivity was $2 \mathrm{mIU} / \mathrm{ml}$ and $\mathrm{CV}$ was below $9 \%$. Adiponectin was measured using a commercially available RIA kit (Linco Research, Inc., St Charles, MO, USA). The assay sensitivity was $1 \mathrm{ng} / \mathrm{ml}$ and intraassay $\mathrm{CV}<9.5 \%$. Insulin resistance was calculated using the homeostasis model assessment of insulin resistance (HOMA index), defined as (fasting immunoreactive insulin in mU/l $\times$ FPG in $\mathrm{mmol} / \mathrm{l}) / 22.5$ (26).

\section{Statistical analysis}

Statistical analysis was performed using the SPSS version 13.0. Data are expressed as mean or as percentage \pm s.D. value. Student's $t$-test was used to compare mean values between men and women. The $\chi^{2}$ test was used to analyze both differences in proportion and distributions of men and women across the seasons. Spearman coefficient of correlation was used to assess linear correlation between $25(\mathrm{OH}) \mathrm{D}$ and other variables. Different models of regression analysis were performed in which $25(\mathrm{OH}) \mathrm{D}$ was studied as an independent variable and each metabolic risk factor as a dependent variable. Finally, and in order to identify an eventual interaction between sex and other variables, regression analysis were performed including the interaction variables. Data were considered statistically significant if $P$ values were $<0.05$.

\section{Results}

Baseline characteristics of the population (clinical and biological parameters) were shown in Table 1 . BMI, WC, SBP, and DBP were all statistically higher in male subjects compared with females $(P<0.0001$ for all variables). In addition, FPG, insulin, HOMA index, and triglycerides were all statistically higher in males compared with females $(P<0.0001, \quad P=0.02$, $P=0.009, \quad P<0.0001$ respectively), while HDLcholesterol and adiponectin were statistically lower $(P<0.0001$ for both variables $)$. 
Table 1 Baseline clinical and biological data of the overall population.

\begin{tabular}{|c|c|c|c|c|}
\hline & Total $(n=381)$ & Men $(n=201)$ & Women $(n=180)$ & $P$ value ${ }^{a}$ \\
\hline \multicolumn{5}{|l|}{ Clinical data } \\
\hline Age (years) & $23.9 \pm 3.9$ & $24.1 \pm 3.9$ & $23.8 \pm 4.0$ & 0.39 \\
\hline BMI $\left(\mathrm{kg} / \mathrm{m}^{2}\right)$ & $23.9 \pm 4.1$ & $25.5 \pm 4.1$ & $22.0 \pm 3.3$ & $<0.0001$ \\
\hline Systolic blood pressure $(\mathrm{mmHg})$ & $110.8 \pm 13.1$ & $117.3 \pm 9.9$ & $103.5 \pm 12.3$ & $<0.0001$ \\
\hline Diastolic blood pressure $(\mathrm{mmHg})$ & $70.5 \pm 9.7$ & $74.3 \pm 8.7$ & $66.3 \pm 9.0$ & $<0.0001$ \\
\hline Waist circumference $(\mathrm{cm})$ & $82.7 \pm 12.2$ & $89.6 \pm 11.0$ & $75.0 \pm 8.4$ & $<0.0001$ \\
\hline $25(\mathrm{OH}) \mathrm{D}(\mathrm{ng} / \mathrm{ml})^{\mathrm{b}}$ & $31.0 \pm 12.5$ & $29.0 \pm 11.2$ & $33.2 \pm 13.4$ & 0.001 \\
\hline Fasting plasma glucose $(\mathrm{mmol} / \mathrm{l})$ & $4.87 \pm 0.27$ & $4.93 \pm 0.29$ & $4.81 \pm 0.23$ & $<0.0001$ \\
\hline Triglycerides $(\mathrm{mmol} / \mathrm{l})$ & $1.05 \pm 0.73$ & $1.19 \pm 0.84$ & $0.89 \pm 0.55$ & $<0.0001$ \\
\hline HDL-cholesterol (mmol/l) & $1.23 \pm 0.31$ & $1.13 \pm 0.27$ & $1.34 \pm 0.31$ & $<0.0001$ \\
\hline Total-cholesterol (mmol/l) & $4.57 \pm 1.03$ & $4.52 \pm 0.98$ & $4.62 \pm 1.08$ & 0.35 \\
\hline LDL-cholesterol (mmol/l) & $2.87 \pm 1.00$ & $2.87 \pm 0.98$ & $2.86 \pm 1.04$ & 0.94 \\
\hline Insulin (mlU/ml) & $9.06 \pm 4.85$ & $9.59 \pm 5.11$ & $8.47 \pm 4.47$ & 0.02 \\
\hline HOMA index & $1.98 \pm 1.10$ & $2.11 \pm 1.17$ & $1.82 \pm 0.99$ & 0.009 \\
\hline
\end{tabular}

Data are expressed as mean \pm s.D.

${ }^{a}$ Comparison between men and women.

${ }^{\mathrm{b}}$ After correction for season and BMI this difference is non-significant.

\section{5(OH)D in relation to clinical, biological parameters, and MetS in the overall population}

25(OH)D in relation to gender, BMI, WC, SBP, DBP, and exercise The mean $25(\mathrm{OH}) \mathrm{D}$ levels in the overall population was $31 \pm 12.48 \mathrm{ng} / \mathrm{ml}$ with a lower mean value in men compared with women $(29.01 \pm 11.23 \mathrm{ng} / \mathrm{ml}$ in men versus $33.2 \pm 13.4 \mathrm{in}$ women, $P=0.001$; Table 1 ). This gender difference disappeared after adjustment for both BMI and season $(P=0.56)$. The adjustment for seasons was performed because the recruitment was not equally balanced between men and women across the seasons $(P=0.001)$. In addition, $25(\mathrm{OH}) \mathrm{D}$ was inversely correlated with BMI, SBP, DBP, and WC $(P=0.001$, $P<0.0001, P=0.004$, and $P<0.0001$ respectively). Finally, there was no significant correlation between $25(\mathrm{OH}) \mathrm{D}$ and exercise score $(r=0.07, P=0.16)$.

25(OH)D in relation to biological parameters 25(OH)D was inversely correlated with FPG, insulin, and HOMA index $(P=0.003, P=0.005, P=0.003$ respectively), and positively correlated with adiponectin and HDL-cholesterol $(P=0.002$ and $P=0.005$ respectively). After adjustment for BMI, the correlation of $25(\mathrm{OH}) \mathrm{D}$ persists for SBP and glucose $(P=0.009$ and $P=0.015$ respectively) but is at the limit of significance for WC $(P=0.08)$, adiponectin $(P=0.11)$, and HDLcholesterol $(P=0.052)$.

In relation to the Mets $25(\mathrm{OH}) \mathrm{D}$ levels do not differ statistically between the 20 MetS positive subjects and the MetS negative ones (respectively $28.65 \pm 15$ vs
$31.1 \pm 12.34 \mathrm{ng} / \mathrm{ml}, P=0.38)$. Also, the correlation between $25(\mathrm{OH}) \mathrm{D}$ levels and the number of MetS risk factors was non-significant $(P=-0.09)$.

\section{$25(\mathrm{OH}) D$ in relation to clinical and biological parameters separately in men and women}

In males, 25(OH)D levels were inversely correlated with BMI, SBP, WC, and LDL-cholesterol $(P=0.02, P=0.01$, $P=0.04$, and $P=0.007$ respectively) and positively correlated with adiponectin $(P=0.01$; Table 2). After adjustment for BMI, the difference persisted for SBP

Table 2 Coefficients of correlation between 25-hydroxyvitamin D and the different studied factors at baseline in the overall population, in men and in women.

\begin{tabular}{lccc}
\hline Parameter & $\begin{array}{c}\text { Overall } \\
\text { population } \\
(n=381)\end{array}$ & $\begin{array}{c}\text { Men } \\
(n=201)\end{array}$ & $\begin{array}{c}\text { Women } \\
(n=180)\end{array}$ \\
\hline BMI $\left(\mathrm{kg} / \mathrm{m}^{2}\right)$ & $-0.17^{\ddagger}$ & $-0.16^{\star}$ & -0.03 \\
$\begin{array}{l}\text { Systolic blood pressure } \\
(\mathrm{mmHg})\end{array}$ & $-0.18^{\ddagger}$ & $-0.18^{\dagger}$ & -0.06 \\
$\begin{array}{l}\text { Diastolic blood pressure } \\
\quad(\mathrm{mmHg})\end{array}$ & $-0.15^{\dagger}$ & -0.13 & -0.05 \\
Waist circumference $(\mathrm{cm})$ & $-0.18^{\ddagger}$ & $-0.15^{\star}$ & -0.09 \\
Fasting plasma glucose & $-0.15^{\dagger}$ & 0.03 & $-0.26^{\ddagger}$ \\
$\quad(\mathrm{mmol} / \mathrm{l})$ & & & \\
Insulin $(\mathrm{mlU} / \mathrm{ml})$ & $-0.145^{\dagger}$ & -0.12 & -0.138 \\
HOMA index & $-0.15^{\dagger}$ & -0.11 & $-0.16^{\star}$ \\
Adiponectin $(\mu \mathrm{g} / \mathrm{ml})$ & $0.16^{\dagger}$ & $0.18^{\dagger}$ & -0.01 \\
Triglycerides $(\mathrm{mmol} / \mathrm{l})$ & 0.02 & 0.04 & 0.06 \\
Total-cholesterol $(\mathrm{mmol} / \mathrm{l})$ & -0.04 & -0.13 & 0.06 \\
LDL-cholesterol $(\mathrm{mmol} / \mathrm{l})$ & -0.08 & $-0.19^{\dagger}$ & 0.002 \\
HDL cholesterol $(\mathrm{mmol} / \mathrm{l})$ & $0.14^{\dagger}$ & 0.11 & 0.08 \\
\hline
\end{tabular}

${ }^{\star} P \leq 0.05,{ }^{\dagger} P \leq 0.01,{ }^{\ddagger} P \leq 0.001$. 
and LDL-cholesterol $(P=0.035$ and $P=0.001)$ but disappeared for $W C$ and adiponectin. In females, 25(OH)D was only inversely correlated with FPG and HOMA index $(P<0.001$ and $P=0.034)$. The correlation with FPG persisted after adjustment for BMI $(P<0.001)$.

In addition, in males, no difference in 25(OH)D levels was observed in the 15 MetS positive male subjects compared with those without the MetS $(P=0.5)$.

We then performed interaction tests comparing men and women for clinical and biochemical parameters. The $P$ value for the interaction test was only significant among all the studied parameters for FPG $(P=0.002)$ and was at the limit of significance for LDL-cholesterol $(P=0.056)$.

Table 3 Association between 25-hydroxyvitamin D and the different studied factors at baseline and after adjustment for sex, body mass index (BMI), and exercise score in the overall population.

\begin{tabular}{lccc}
\hline Parameter & B2 & s.E.M. & Significance \\
\hline Systolic blood pressure $(\mathrm{mmHg})$ & & \\
Model 0 & -0.0201 & 0.0053 & $<0.0001$ \\
Model 1 & -0.0112 & 0.0046 & 0.015 \\
Model 2 & -0.0085 & 0.0045 & 0.05 \\
Model 3 & -0.0076 & 0.0045 & 0.09 \\
Diastolic blood pressure $(\mathrm{mmHg})$ & & \\
Model 0 & -0.0109 & 0.0040 & 0.006 \\
Model 1 & -0.0057 & 0.0037 & 0.12 \\
Model 2 & -0.0032 & 0.0035 & 0.36 \\
Model 3 & -0.0021 & 0.0035 & 0.56 \\
Waist circumference $(\mathrm{cm})$ & -0.1867 & 0.0493 & $<0.0001$ \\
Model 0 & -0.0917 & 0.0407 & 0.025 \\
Model 1 & -0.0151 & 0.0197 & 0.44 \\
Model 2 & -0.0025 & 0.0195 & 0.89 \\
Model 3 & & \\
Fasting plasma glucose (mmol/l) & & \\
Model 0 & -0.0050 & 0.0011 & 0.003 \\
Model 1 & -0.0026 & 0.0011 & 0.018 \\
Model 2 & -0.0024 & 0.0011 & 0.032 \\
Model 3 & -0.0023 & 0.0012 & 0.037 \\
Insulin (mlU/ml) & & & \\
Model 0 & -0.0562 & 0.0197 & 0.005 \\
Model 1 & -0.0501 & 0.0199 & 0.012 \\
Model 2 & -0.0278 & 0.0171 & 0.10 \\
Model 3 & -0.0249 & 0.0173 & 0.15 \\
HOMA index & & & \\
Model 0 & -0.0134 & 0.0045 & 0.003 \\
Model 1 & -0.0118 & 0.0045 & 0.009 \\
Model 2 & -0.0068 & 0.0039 & 0.08 \\
Model 3 & -0.0061 & 0.0039 & 0.12 \\
Adiponectin ( $\mu \mathrm{gg} / \mathrm{ml})$ & & \\
Model 0 & 0.0755 & 0.0258 & 0.004 \\
Model 1 & 0.0280 & 0.0218 & 0.20 \\
Model 2 & 0.0146 & 0.0211 & 0.49 \\
Model 3 & 0.0113 & 0.0214 & 0.60 \\
HDL-cholesterol $(\mathrm{mmol} / \mathrm{l})$ & & \\
Model 0 & 0.0035 & 0.0013 & 0.008 \\
Model 1 & 0.0019 & 0.0012 & 0.11 \\
Model 2 & 0.0017 & 0.0012 & 0.16 \\
Model 3 & 0.0015 & 0.0012 & 0.23 \\
\hline Model 0 at bsel & & \\
\hline
\end{tabular}

Model 0 , at baseline; Model 1, after adjustment for sex; Model 2, after adjustment for sex and BMI; Model 3, after adjustment for sex, BMI and exercise score.

\section{Multivariate regression analysis models looking at 25(OH)D as an explanatory variable for each of the metabolic risk factors}

Separate regression analysis was performed where each of the metabolic risk factors was introduced as a dependent variable and $25(\mathrm{OH}) \mathrm{D}$ as an independent variable (Table 3). Only the variables that were at baseline significantly correlated with $25(\mathrm{OH}) \mathrm{D}$ $(P<0.05)$ in Table 2 were analyzed. Each regression was performed at baseline (model 0), after adjustment for sex (model 1), sex and BMI (model 2) and, finally, sex, BMI and exercise score (model 3). 25(OH)D was found to be an independent predictor of both FPG and SBP after adjustment for sex and BMI $(P=0.032$ and $P=0.05)$. After a further adjustment for exercise score, the significance persisted for FPG $(P=0.037)$ but was at the limit of significance for SBP $(P=0.09)$. A similar approach was performed in the male population (data not shown in tables). After adjustment for only BMI, 25(OH)D predicted both SBP and LDL-cholesterol ( $P=0.035$ and $P=0.009$ respectively), while after adjustment for both BMI and exercise score, the significance persisted for LDL cholesterol $(P=0.007)$ but was at the limit for SBP $(P=0.07)$.

\section{Discussion}

Our study investigated in a young healthy non-diabetic population the relations between 25(OH)D levels and both adiponectin and several metabolic risk factors such as BMI, WC, SBP, HOMA index, and lipid profile.

The main new finding of the present study is the positive association between $25(\mathrm{OH}) \mathrm{D}$ and adiponectin. After adjustment for sex, BMI, and exercise score, this association disappears, similar to the results of the Liu report (24). Although after adjustment for BMI this association is non-significant $(P=0.11)$, one cannot exclude a possible direct association between these two variables. In fact, a previous in vitro study found that calcium and 1,25-dihydroxyvitamin $\mathrm{D}_{3}$ regulate the expression of adipokine in visceral fat (27), suggesting that vitamin $\mathrm{D}$ may upregulate the adiponectin gene. The association between vitamin $\mathrm{D}$ and adiponectin may be also mediated by cytokines since $1,25(\mathrm{OH}) 2 \mathrm{D}$ plays a role in dawn regulating the tumor necrosis factor $\alpha$-gene (28) which is one of the factors that affects the adiponectin synthesis (29). Because adiponectin has a protective role against atherosclerosis (30), one can speculate that the cardiovascular protective effect of vitamin $\mathrm{D}$ is partly mediated by adiponectin. The reason behind the gender difference we observe in this relation is unclear. Because decreased levels of adiponectin are found in men compared with women (31) and this may be androgen induced (32), an interaction between sex steroids and vitamin $\mathrm{D}$ in the adiponectin gene regulation may exist. 
In addition, our study shows in the overall population a significant inverse correlation between 25(OH)D levels and HOMA index, FPG and insulin levels; this relation is independent of BMI for FPG levels, and is non-significant in our male population. The reason for the weak and non-significant relation in males is unclear. It is possible that an increase in the sample size might lead to significant correlations. Several observations have linked vitamin D deficiency to alterations in glucose metabolism $(11,12)$. Cross-sectional studies have shown inverse correlations between $25(\mathrm{OH}) \mathrm{D}$ levels and both fasting serum glucose $(12,24)$ and insulin resistance $(13-15,24)$. However, all these studies were mainly performed in older adults $(12,15,21,23,24)$ or in obese subjects (either obese children and adolescents (14) or obese adults $(33,34)$ ). In addition, after adjustment for BMI, the vitamin D relation to insulin resistance was found to be independent of BMI in elderly non-diabetic men (15) and non-diabetic adults (24), while, on the contrary, in obese subjects (34), the association between vitamin D and the MetS lost its significance after adjustment for BMI and fat mass. The only study that was performed in glucose-tolerant young subjects revealed an independent negative association between 25(OH)D levels and plasma glucose during an oral glucose tolerance test (13). Moreover, in this last study, there was also an independent correlation between $25(\mathrm{OH}) \mathrm{D}$ and insulin sensitivity index measured by a hyperglycemic clamp (13). The reason for these discrepant results could be the nature of the studied cohorts, or the way insulin sensitivity assessment was made. Finally, a recent interventional study (35) showed that in adults without diabetes, correction of vitamin D deficiency is not associated with any effect on blood glucose or insulin sensitivity (assessed by an oral glucose tolerance test), adding more controversies to the subject.

Independent of BMI, we found an inverse relationship between SBP and 25(OH)D. This finding was observed in our overall population as well as in our male population. The relation between vitamin $\mathrm{D}$ and blood pressure has also been the subject of several publications (8-10). In one of these studies (10), both SBP and DBP were higher in vitamin D deficient subjects, but only SBP was an independent predictor of vitamin D deficiency after adjustment for BMI, a finding that has been confirmed in our study. In another study (9), obese children and adolescents with vitamin D insufficiency had increased SBP. Finally, results from an interventional study (8) showed that, in hypertensive subjects exposed to u.v. B radiation three times a week, a significant reduction of both SBP and DBP by $6 \mathrm{mmHg}$ was observed. A plausible mechanism for the association between vitamin D deficiency and high blood pressure is an activation of the renin-angiotensin system. In fact, calcitriol is known to be a negative endocrine regulator of this system (36). At the opposite, serum $25(\mathrm{OH}) \mathrm{D}$ was not associated with blood pressure in older Dutch men and women, possibly due to the relatively high $25(\mathrm{OH})$ D levels in this population (37).

Finally, we found in our male population that, independent of BMI, high LDL-cholesterol was associated with vitamin D insufficiency. This association was not found in the overall population. The relation between $25(\mathrm{OH}) \mathrm{D}$ and lipid profile has also been the subject of several reports. In the Chiu et al. study (13), an independent negative correlation of $25(\mathrm{OH}) \mathrm{D}$ concentration with total and LDL-cholesterol was observed. In another study (9), obese children and adolescents with vitamin D insufficiency had decreased HDL-cholesterol. Finally, more recently, in healthy young subjects, a significant negative correlation was observed between $25(\mathrm{OH}) \mathrm{D}$ and the ratio of LDL/HDL-cholesterol (38). Results of all of these studies are in line with what we have found in our male population. It is plausible that u.v.-irradiation has a beneficial effect on lipids through the photo conversion of 7-dehydrocholesterol to lumisterol (39). It is also possible that an influx of cholesterol from plasma lipoproteins could increase 7-dehydrocholesterol concentrations which in turn increase vitamin D synthesis.

The reason for the gender difference we observe in relation between vitamin $\mathrm{D}$ and metabolic risk factors is unknown. The young age and the low BMI of our female population could be explanatory factors. The sex steroid environment could also play a role. Finally, this difference may disappear if we either increase the sample size of the female population, or if we include a female population with higher BMI, since only the FPG led to a significant interaction when comparing men and women. Our findings are in line with the results of another study (21) in which a sex difference in the parathyroid hormone (PTH)-MetS association was observed. In that study (21), an increased risk of MetS with elevated PTH was observed in older men but not in women.

Our study may present certain limitations. First, it was performed in a young subgroup of the Lebanese population with high educational level, and subsequently with relative adequate vitamin $\mathrm{D}$ status. This finding may weaken the relation between $25(\mathrm{OH}) \mathrm{D}$ levels and metabolic risk factors, more particularly in our female population. In addition, our study is limited by the cross-sectional nature of its data, which impedes the ability to infer causability between vitamin D and those risk factors. Finally, our relative small sample size compared with other larger crossectional surveys may also limit the ability to detect significant associations.

In conclusion, this study looked for the first time at the relation between vitamin D status and multiple metabolic risk factors in non-obese young subjects. We find a clear relation between $25(\mathrm{OH}) \mathrm{D}$ levels and both FPG and SBP in our overall population, while in addition in males $25(\mathrm{OH}) \mathrm{D}$ is associated with LDL-cholesterol. More importantly, we describe a new positive relation between adiponectin and 25(OH)D. This finding should be further looked at in other populations, either by crosssectional or interventional studies. 


\section{Declaration of interest}

The authors declare that there is no conflict of interest that could be perceived as prejudicing the impartiality of the research reported.

\section{Funding}

This work was supported by grants from the Conseil de la Recherche de l'Université Saint-Joseph (FM160 and FM122).

\section{References}

1 Holick MF. Vitamin D deficiency. New England Journal of Medicine $2007357266-281$.

2 Zittermann A. Vitamin D and disease prevention with special reference to cardiovascular disease. Progress in Biophysics and Molecular Biology 200692 39-48.

3 Michos ED \& Melamed ML. Vitamin D and cardiovascular disease risk. Current Opinion in Clinical Nutrition and Metabolic Care 2008 $117-12$.

4 Martins D, Wolf M, Pan D, Zadshir A, Tareen N, Thadhani R, Felsenfeld A, Levine B, Mehrotra R \& Norris K. Prevalence of cardiovascular risk factors and the serum levels of 25-hydroxyvitamin D in the United States: data from the Third National Health and Nutrition Examination Survey. Archives of Internal Medicine 2007167 1159-1165.

5 Pittas AG, Lau J, Hu FB \& Dawson-Hughes B. The role of vitamin D and calcium in type 2 diabetes. A systematic review and metaanalysis. Journal of Clinical Endocrinology and Metabolism 200792 2017-2029.

6 Hyppönen E \& Power C. Vitamin D status and glucose homeostasis in the 1958 British birth cohort: the role of obesity. Diabetes Care $2006292244-2246$.

7 Rostand SG. Ultraviolet light may contribute to geographic and racial blood pressure differences. Hypertension 199730 150-156.

8 Krause R, Bühring M, Hopfenmüller W, Holick MF \& Sharma AM. Ultraviolet B and blood pressure. Lancet 1998352 709-710.

9 Smotkin-Tangorra M, Purushothaman R, Gupta A, Nejati G, Anhalt H \& Ten S. Prevalence of vitamin D insufficiency in obese children and adolescents. Journal of Pediatric Endocrinology and Metabolism 200720 817-823.

10 Scragg R, Sowers M \& Bell C. Serum 25-hydroxyvitamin D, ethnicity, and blood pressure in the Third National Health and Nutrition Examination Survey. American Journal of Hypertension $200720713-719$

11 Tai K, Need AG, Horowitz M \& Chapman IM. Vitamin D, glucose, insulin, and insulin sensitivity. Nutrition 200824 279-285.

12 Need AG, O'Loughlin PD, Horowitz M \& Nordin BE. Relationship between fasting serum glucose, age, body mass index and serum 25 hydroxyvitamin D in postmenopausal women. Clinical Endocrinology 200562 738-741.

13 Chiu KC, Chu A, Go VL \& Saad MF. Hypovitaminosis D is associated with insulin resistance and beta cell dysfunction. American Journal of Clinical Nutrition 200479 820-825.

14 Alemzadeh R, Kichler J, Babar G \& Calhoun M. Hypovitaminosis D in obese children and adolescents: relationship with adiposity, insulin sensitivity, ethnicity, and season. Metabolism $2008 \mathbf{5 7}$ 183-191.

15 Baynes KC, Boucher BJ, Feskens EJ \& Kromhout D. Vitamin D, glucose tolerance and insulinaemia in elderly men. Diabetologia 199740 344-347.

16 Scragg R, Sowers M \& Bell C. Third National Health and Nutrition Examination Survey. Serum 25-hydroxyvitamin D, diabetes, and ethnicity in the Third National Health and Nutrition Examination Survey. Diabetes Care 200427 2813-2818.

17 Palomer X, González-Clemente JM, Blanco-Vaca F \& Mauricio D. Role of vitamin $\mathrm{D}$ in the pathogenesis of type 2 diabetes mellitus. Diabetes, Obesity and Metabolism 200810 185-197.
18 Ford ES, Ajani UA, McGuire LC \& Liu S. Concentrations of serum vitamin $\mathrm{D}$ and the metabolic syndrome among US adults. Diabetes Care 200528 1228-1230.

19 Hyppönen E, Boucher BJ, Berry DJ \& Power C. 25-Hydroxyvitamin D, IGF-1, and metabolic syndrome at 45 years of age: a crosssectional study in the 1958 British Birth Cohort. Diabetes 200857 298-305.

20 McGill AT, Stewart JM, Lithander FE, Strik CM \& Poppitt SD. Relationships of low serum vitamin D3 with anthropometry and markers of the metabolic syndrome and diabetes in overweight and obesity. Nutrition Journal $200874-8$

21 Reis JP, von Mühlen D, Kritz-Silverstein D, Wingard DL \& Barrett-Connor E. Vitamin D, parathyroid hormone levels, and the prevalence of metabolic syndrome in community-dwelling older adults. Diabetes Care 200730 1549-1555.

22 de Boer IH, Tinker LF, Connelly S, Curb JD, Howard BV, Kestenbaum B, Larson JC, Manson JE, Margolis KL, Siscovick DS \& Weiss NS. Women's Health Initiative Investigators. Calcium plus vitamin D supplementation and the risk of incident diabetes in the Women's Health Initiative. Diabetes Care 200831 701-707.

23 Pittas AG, Harris SS, Stark PC \& Dawson-Hughes B. The effects of calcium and vitamin D supplementation on blood glucose and markers of inflammation in nondiabetic adults. Diabetes Care 2007 30 980-986.

24 Liu E, Meigs JB, Pittas AG, McKeown NM, Economos CD, Booth SL \& Jacques PF. Plasma 25-hydroxyvitamin D is associated with markers of the insulin resistant phenotype in nondiabetic adults. Journal of Nutrition 2009139 329-334.

25 National Cholesterol Education Program (NCEP). Expert panel on detection, evaluation, and treatment of high blood cholesterol in adults (Adult Treatment Panel III). Circulation 2002106 3143-3421.

26 Vaccaro O, Masulli M, Cuomo V, Albarosa Rivellese A, Uusitupa M, Vessby B. Hermansen K. Tapsell L \& Riccardi G. Comparative evaluation of simple indices of insulin resistance. Metabolism 2004 53 1522-1526.

27 Sun X \& Zemel MB. Calcium and 1,25-dihydroxyvitamin D regulation of adipokine expression. Obesity 200715 340-348.

28 Cantorna MT \& Mahon BD. D-hormone and the immune system. Journal of Rheumatology 200576 11-20.

29 Ruan H \& Lodish HF. Insulin resistance in adipose tissue: direct and indirect effects of tumor necrosis factor-alpha. Cytokine and Growth Factor Reviews 200314 447-455.

30 Matsuda M, Shimomura I, Sata M, Arita Y, Nishida M, Maeda N, Kumada M, Okamoto Y, Nagaretani H, Nishizawa H, Kishida K, Komuro R, Ouchi N, Kihara S, Nagai R, Funahashi T \& Matsuzawa Y. Role of adiponectin in preventing vascular stenosis The missing link of adipo-vascular axis. Journal of Biological Chemistry 2002277 37487-37491.

31 Arita Y, Kihara S, Ouchi N, Takahashi M, Maeda K, Miyagawa J. Hotta K, Shimomura I, Nakamura T, Miyaoka K, Kuriyama H, Nishida M, Yamashita S, Okubo K, Matsubara K, Muraguchi M, Ohmoto Y, Funahashi T \& Matsuzawa Y. Paradoxical decrease of an adipose-specific protein, adiponectin, in obesity. Biochemical and Biophysical Research Communications 1999257 79-83.

32 Nishizawa H, Shimomura I, Kishida K, Maeda N, Kuriyama H, Nagaretani H, Matsuda M, Kondo H, Furuyama N, Kihara S, Nakamura T, Tochino Y, Funahashi T \& Matsuzawa Y. Androgens decrease plasma adiponectin, an insulin-sensitizing adipocytederived protein. Diabetes $2002512734-2741$.

33 Botella-Carretero JI, Alvarez-Blasco F, Villafruela JJ, Balsa JA, Vázquez C \& Escobar-Morreale HF. Vitamin D deficiency is associated with the metabolic syndrome in morbid obesity. Clinical Nutrition 200726 573-580.

34 Rueda S, Fernández-Fernández C, Romero F, Martínez de Osaba J \& Vidal J. Vitamin D, PTH and the metabolic syndrome in severely obese subjects. Obesity Surgery 200818 151-154.

35 Tai K, Need AG, Horowitz M \& Chapman IM. Glucose tolerance and vitamin D: effects of treating vitamin D deficiency. Nutrition 200822 950-956. 
$36 \mathrm{Li} \mathrm{YC.} \mathrm{Vitamin} \mathrm{D} \mathrm{regulation} \mathrm{of} \mathrm{the} \mathrm{renin-angiotensin} \mathrm{system.}$ Journal of Cellular Biochemistry $2003 \mathbf{8 8} 327-331$.

37 Snijder MB, Lips P, Seidell JC, Visser M, Deeg DJ, Dekker JM \& van Dam RM. Vitamin D status and parathyroid hormone levels in relation to blood pressure: a population-based study in older men and women. Journal of Internal Medicine 2007 261 558-565.

38 Carbone LD, Rosenberg EW, Tolley EA, Holick MF, Hughes TA, Watsky MA, Barrow KD, Chen TC, Wilkin NK, Bhattacharya SK, Dowdy JC, Sayre RM \& Weber KT. 25-Hydroxyvitamin D, cholesterol, and ultraviolet irradiation. Metabolism 200857 741-748.
39 Slominski A, Zjawiony J, Wortsman J, Semak I, Stewart J, Pisarchik A, Sweatman T, Marcos J, Dunbar C \& Tuckey RC. A novel pathway for sequential transformation of 7-dehydrocholesterol and expression of the P450scc system in mammalian skin. European Journal of Biochemistry 2004271 4178-4188.

Received 3 March 2009

Accepted 15 March 2009 